\title{
Value or cost: looking for the wider perspective
}

\section{Phil Wiffen}

Oscar Wilde once described a cynic as one who knows the price of everything and the value of nothing. While not agreeing with all of that statement, it is easy for pharmacists to become obsessed with cost rather than value (though they see this as a professional responsibility not in a cynical way). Two scenarios come to mind. The first is theoretical in that while reviewing a paper looking at antibiotic prophylaxis for long-term urinary catheters in elderly patients, pharmacists expressed the view that the cost of the antibiotics was not justified. They failed to consider the impact of just one life-threatening urinary tract infection which could cost a patient his/her life (what price do we put on that?). In a second real situation, a patient with a neuropathic pain in his thumb was recommended a treatment by a consultant. The patient's general practitioner on advice from a pharmaceutical adviser was told that the treatment was too expensive, and so was not prescribed. The patient tried a number of other treatments, none of which worked. In desperation, he persuaded a surgeon to remove the thumb. The pain did not go away. The patient was sent back to the original consultant who made the same recommendation. Understanding the value of healthcare products and interventions is vital but not well defined. A recent review article looked for literature on this topic looking for papers on nine European Union countries. ${ }^{1}$

The authors posed two questions: How is healthcare value defined? They looked at different stakeholders including health technology assessment (HTA), reimbursement agencies, clinicians, providers and patients. Second, they wanted to know how the countries of interest incorporated the value into assessment and decision making. A wide search was undertaken both on the medical databases and also on a number of relevant websites for organisations and HTA bodies. They identified some 231 relevant papers.

Three definitions of value were uncovered. The one of most relevance to pharmacists is: The value of a new health technology can be described by a set of product attributes relating to its efficacy,

Correspondence to Professor Phil Wiffen, Pain Research Unit, Churchill Hospital, Oxford, UK; phil. wiffen@ndcn.ox.ac.uk safety, impact on quality of life and functional status, dosing convenience and pricing, compared with the current standard of care.

What emerges is that there is no single shared definition of value. In fact, value seems to depend on who you are talking to. Patients are mainly concerned with the effectiveness and safety of a treatment and consider long-term adverse effects to be the most significant downsides of a treatment choice. Clinicians think similarly but also add potential cost savings from better treatments and severity of an underlying condition. Healthcare managers put high regard on health outcomes and safety but were also concerned about cost and required staff resources. Payers value the treatment with the lowest cost.

Review authors then go on to discuss how value might be used in decision making. They report that France, Germany and Italy make reimbursement decisions based on the clinical benefits and only consider cost at a later pricing stage. Others-Austria, Hungary, the Netherlands, Spain, Sweden and the UK-carry out an economic evaluation as part of the clinical assessment. Quality-adjusted life year (QALY) is the measure of value most widely used.

While the concept of a QALY is simple, in practice it is not easy to calculate or even understand. The assumption is made that 1 year lived in perfect health is worth one QALY. ${ }^{2}$ It follows therefore that less than perfect health equates to less than one QALY. While useful, there are lots of aspects that are not captured such as equity considerations, adherence to medicines, effect on carers, ability to return to work or live independently. For some technologies, society benefits may need to be considered. Not surprisingly, the QALY has led to the concept of a cost per QALY as a means of assessing and comparing treatments. Across the nine countries, the majority settle around an upper limit of $€ 20000-€ 30000$ per QALY though for severe diseases some will go above this. Other models exist such as value-based pricing (VBP) and multicriteria decision analysis (MCDA). VBP has a range of definitions but basically is an approach to arrive at pricing based on therapeutic value, economic value and cost effectiveness. ${ }^{3}$ MCDA is another approach to compare, prioritise and select criteria in the assessment of healthcare products using a systematic and transparent approach; ${ }^{4}$ however, concerns have been expressed about choosing and scoring the criteria. Returning to our original neuropathic pain patient, it is likely that a more sensible decision could have been made if the decision makers had looked for papers such as 'The costs and consequences of adequately managed chronic non-cancer pain and chronic neuropathic pain'. 5

So what does this mean for hospital pharmacists who are involved in formulary decisions or medicine evaluation? Time needs to be taken to seek to understand the wider picture and be aware of patent perspectives. While it is attractive to find a 'one solution to fit all' in formulary decisions, in practice, hospital formularies-based on cost alone-are too restrictive for good care.

Asking about the cost is no longer the right question. What is it worth? or what is its value? would be wiser.

\section{EAHP Statement 6: Education and} Research

\section{Competing interests None declared.}

Provenance and peer review Commissioned; internally peer reviewed.

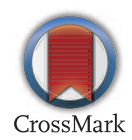

To cite Wiffen P. Eur J Hosp Pharm 2017;24:73.

Eur J Hosp Pharm 2017;24:73.

doi:10.1136/ejhpharm-2017-001213

\section{REFERENCES}

1 Antoñanzas F, Terkola R, Postma M. The value of medicines: a crucial but vague concept. Pharmacoeconomics 2016:34:1227-39.

2 Prieto L, Sacristán JA. Problems and solutions in calculating quality-adjusted life years (QALYs). Health Qual Life Outcomes 200319;i1:80.

3 Hulshof JA. Sustainable health care systems: the role of therapeutic value and value based pricing Value Health 2014;17:A452.

4 Broekhuizen H, Groothuis-Oudshoorn CG, van Til JA, et al. A review and classification of approaches for dealing with uncertainty in multi-criteria decision analysis for healthcare decisions. Pharmacoeconomics 2015;33:445-55.

5 Andrew R, Derry S, Taylor RS, et al. The costs and consequences of adequately managed chronic noncancer pain and chronic neuropathic pain. Pain Pract 2014;14:79-94. 